\title{
Erratum to: Crime Patterns between Tradition and Change: A Territorial Analysis of the Italian Provinces
}

\section{Luigi M. Solivetti ${ }^{1}$}

Published online: 20 February 2016

(C) Springer Science+Business Media Dordrecht 2016

\section{Erratum to: Social Indicators Research DOI 10.1007/s11205-015-1043-1}

Unfortunately the values in Tables 1 and 4 were published incorrectly. The corrected Tables 1 and 4 are given in this erratum.

The online version of the original article can be found under doi:10.1007/s11205-015-1043-1.

Luigi M. Solivetti

luigi.solivetti@uniroma1.it

1 Department of Social Sciences and Economics, Sapienza University of Rome, Piazzale A. Moro, 5, 00185 Rome, Italy 


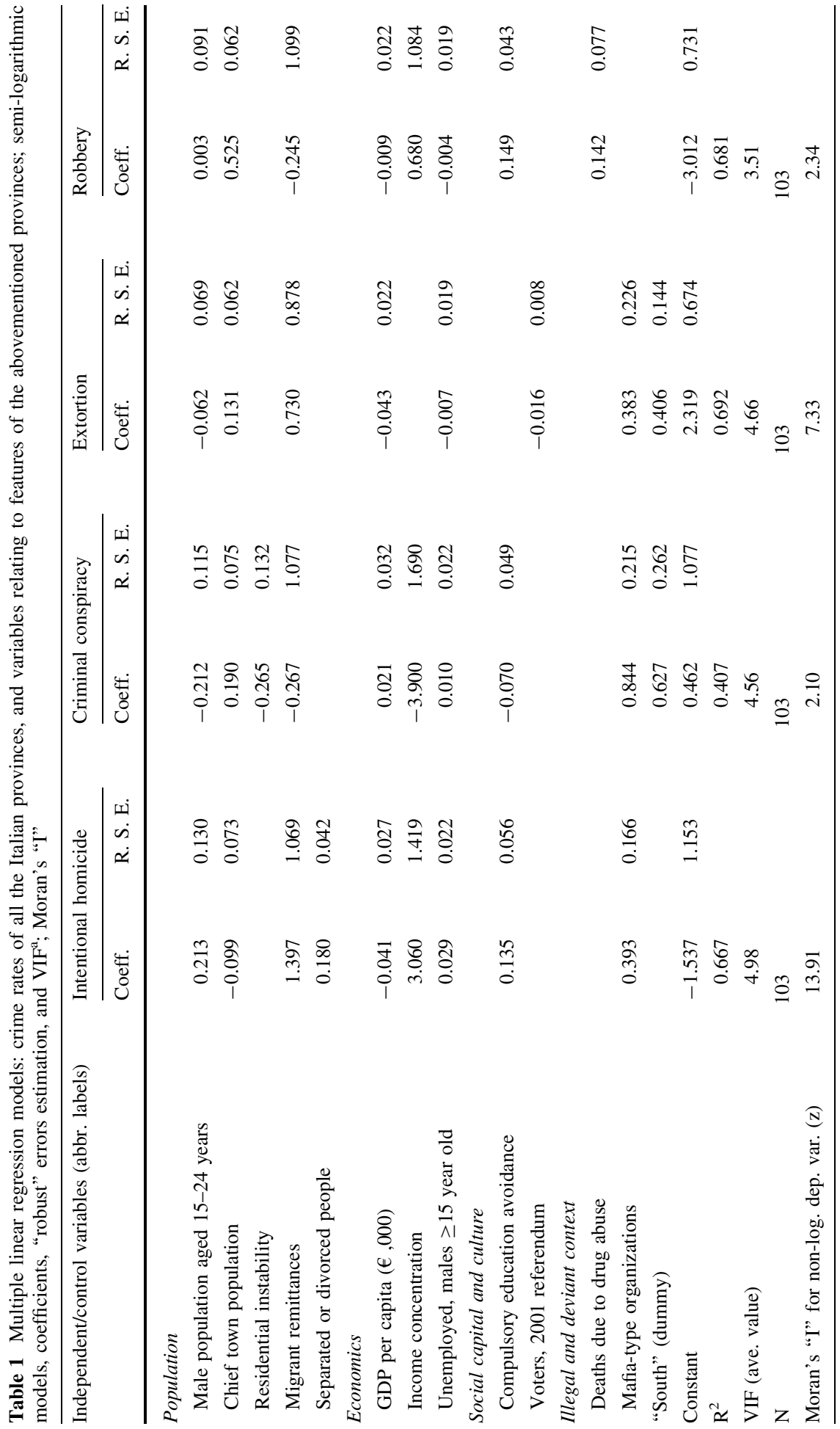




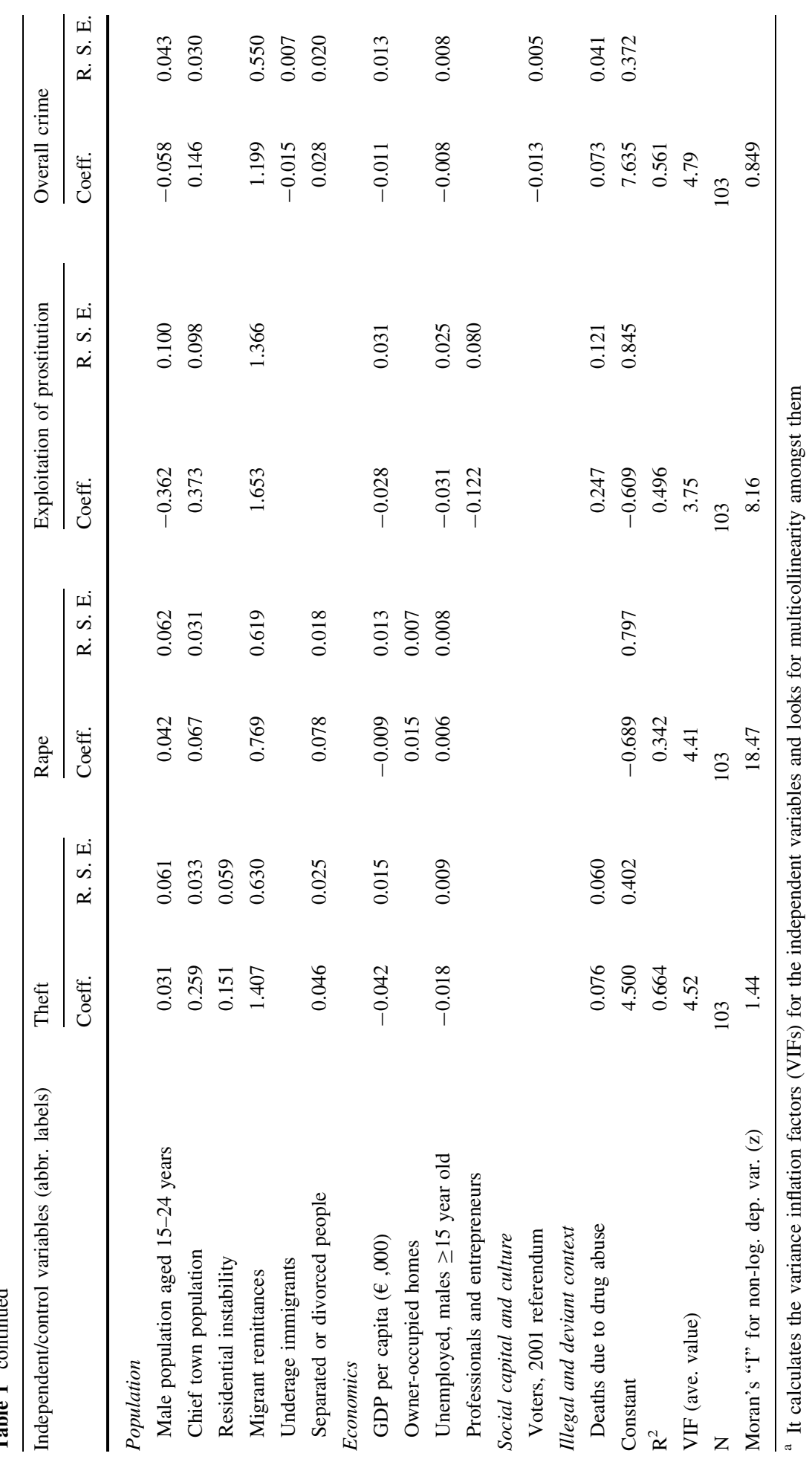




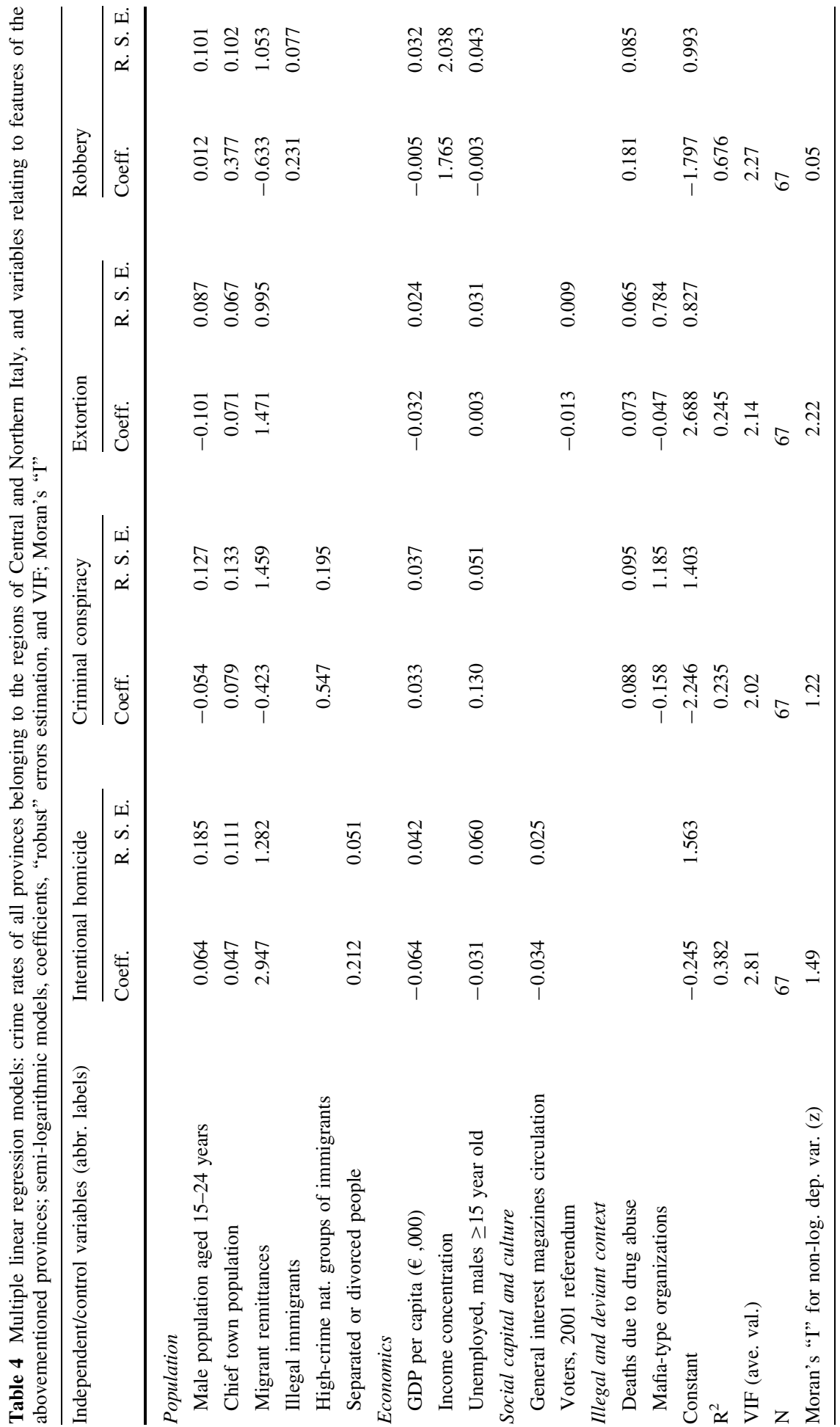




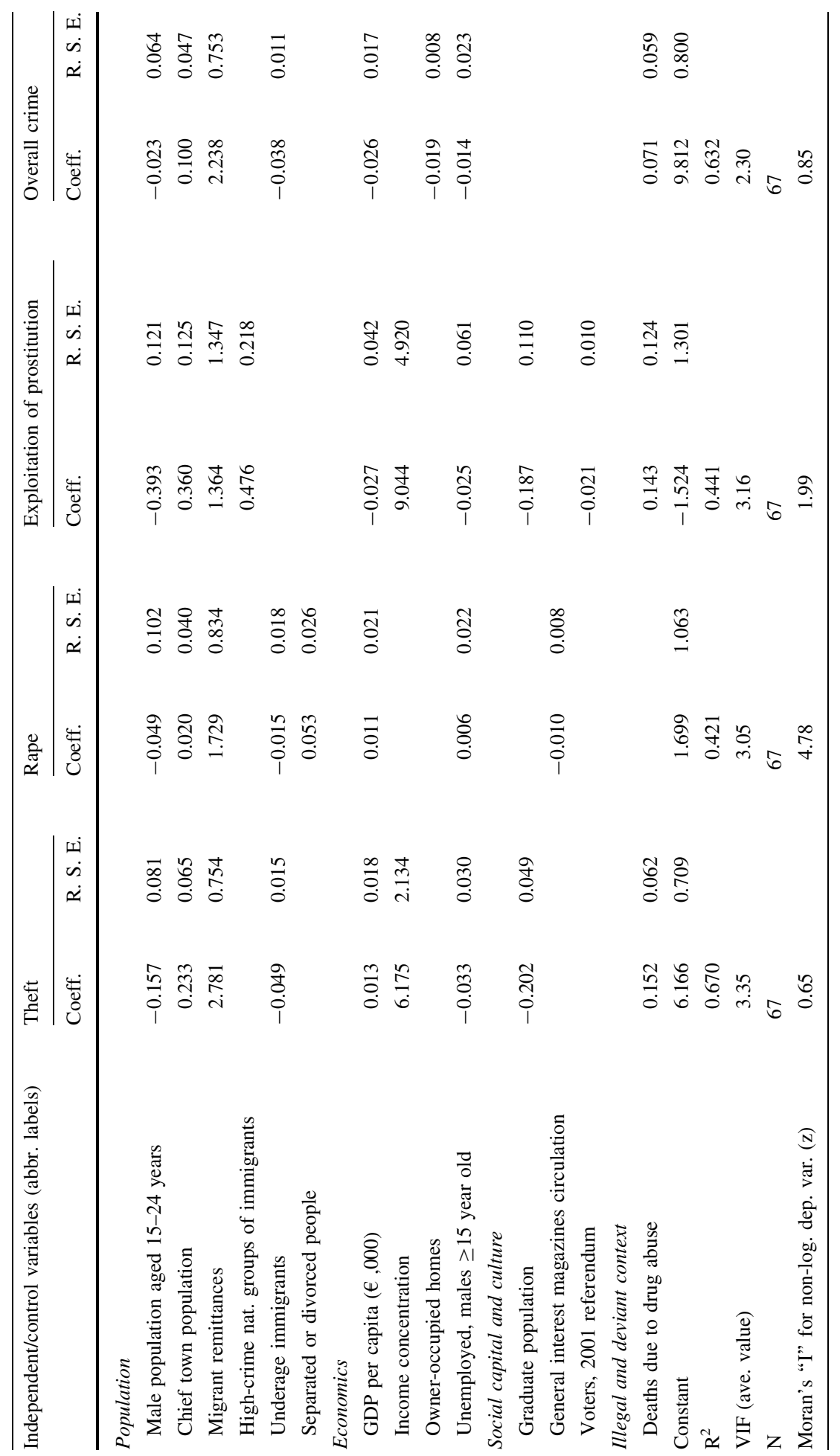

